\title{
Assessment of Knowledge of Acute Kidney Injury among Non- Nephrology Doctors in Two Government Hospitals in Ondo City, Southwest, Nigeria
}

\section{Oluseyi Adejumo*, Ayodeji Akinbodewa, Oladimeji Alli, Pirisola Olufemi, Abolarin Olatunji}

\footnotetext{
OPEN ACCESS

Citation: Oluseyi Adejumo, Ayodeji Akinbodewa, Oladimeji Alli, Pirisola Olufemi, Abolarin Olatunji. Assessment of Knowledge of Acute Kidney Injury among Non-Nephrology Doctors in Two Government Hospitals in Ondo City, Southwest, Nigeria. Ethiop J Health Sci 2017;27(1): 147.

http://dx.doi.org/10.4314/ejhs.v27i2.7

Received: November 17, 2016

Accepted: November 21, 2016

Published: March 1, 2017

Copyright: (C) 2017 Adejumo O. et al.

This is an open access article distributed under the terms of the Creative Commons

Attribution License, which permits unrestricted use, distribution, and reproduction in any medium, provided the original author and source are credited.

Funding: Nill

Competing Interests: The authors

declare that this manuscript was approved by all authors in its form and that no

competing interest exists.

Affiliation and Correspondence:

Kidney Care Centre, University of

Medical Sciences Ondo, Ondo State,

Nigeria

"Email: ceeward2010@yahoo.com
}

\begin{abstract}
BACKGROUND: Adequate knowledge of acute kidney injury (AKI) among doctors is essential for its prevention, early diagnosis and management. Assessing knowledge of AKI among doctors is necessary to identify areas of deficiencies and key areas to be emphasized when organizing educational programs aimed at improving AKI care. This study determined the knowledge of AKI among non-nephrology doctors in Ondo City, Southwest Nigeria. MATERIALS AND METHODS: This was a cross-sectional descriptive study carried out in two government hospitals in Ondo City using a self-administered pretested questionnaire that assessed knowledge of AKI among non-nephrology doctors. P-value of $<$ 0.05 was taken as significant.

RESULTS: Eighty-one doctors participated in the study with a median post-graduation experience of 5.5 years. Sixty-one (78.2\%) were in surgical specialty while the remaining worked in medical specialty. Only 1(1.2\%) of the respondents had good knowledge of AKI, 56(69.2\%) had fair knowledge while the remaining 24 (29.6\%) had poor knowledge of AKI. Identified areas of deficiencies in knowledge of AKI were in mode of presentation, risk factors, potentially nephrotoxic medications, criteria for AKI definition and staging, newer AKI biomarkers and indications for renal replacement therapy. There was no significant association between knowledge of AKI and specialty $(p=0.593)$ or year of practice $(p=0.312)$

CONCLUSION: There were significant deficiencies in the knowledge of AKI amongst most non-nephrology doctors in Ondo city. We therefore recommend regular in-service training on AKI for practicing doctors.

KEYWORDS: Knowledge, Non-nephrology doctors, Acute Kidney Injury
\end{abstract}

\section{INTRODUCTION}

Acute Kidney Injury (AKI) is an increasingly important health problem both in developing and developed countries (1-3). Susantitaphong et al reported the pooled incidence of AKI in adults

DOI: http://dx.doi.org/10.4314/ejhs.v27i2.7 
to be $22 \%$ from met-analysis of studies that were mainly from Asia, America and Europe (2). The incidence of AKI also ranges between 30-70\% among critically ill patients (4). It is the most common reason for in-hospital nephrology consultation in the United States (3). The burden of AKI is quite enormous due to associated morbidity, mortality, prolonged hospital stay and increase in overall health expenditure (4-6).

Acute kidney injury is an important risk factor for chronic kidney disease (CKD), rapid progression to end stage renal disease later in life and long term non-renal morbidity and mortality $(7,8)$. Even a small increase in serum creatinine is associated with increased morbidity and mortality. Hence, there is a need for timely diagnosis and management of AKI (9).

Previous reports have shown deficiencies in risk identification, prevention, early diagnosis and satisfactory management of AKI among health workers (10-13). Aitken et al reported that about a quarter of patients on admission had AKI that was unrecognized in Glasgow, United Kingdom (11). The United Kingdom National Confidential Enquiry into Patients' Outcomes and Death (NCEPOD) reported that about $50 \%$ of patients who died of AKI did not receive good medical care and $43 \%$ of patients who developed AKI while on admission had delay in diagnosis (10). Also, Evans et al reported that the majority of health workers in Malawi were not confident in managing AKI due to clinical inexperience and deficiencies in their knowledge of AKI management (12).

The majority of AKI patients are initially managed by non-specialists due to scarcity of nephrologists globally in relation to the prevalence of AKI (14). This is corroborated by previous reports which showed that less than a third of patients with AKI were seen by nephrologists $(10,15)$. Adequate knowledge of AKI is therefore required among health workers especially doctors in order to ensure timely diagnosis and effective management of AKI patients. This will reduce the associated morbidity, mortality and cost of care which is mostly solely borne by patients and relatives in developing countries unlike in developed countries where there is health insurance scheme that caters for the medical bills. Assessing knowledge of AKI among doctors is therefore necessary to identify areas of knowledge gaps where emphasis should be placed in organizing educational programs aimed at improving AKI care. This study therefore assessed the knowledge of AKI among non-nephrology doctors in two government hospitals in Ondo City, Southwest Nigeria.

\section{MATERIAL AND METHODS}

Study setting and participants: This was a crosssectional descriptive study carried out over a six week period in the two government hospitals in Ondo City, Southwest Nigeria: Ondo state medical village and State Specialist hospital, Ondo city between April and May 2016. A simple random technique was adopted in selecting the participants who were doctors working in the two government hospitals in Ondo City.

Sample size calculation: The minimum sample size for this study was 80 after including $10 \%$ attrition rate using Epi Info sample size calculator for a population less than 10,000. Fifty percent was taken as the proportion with adequate knowledge of AKI and 95\% was used as the confidence interval. Eighty-one respondents participated in the study with a response rate of $90 \%$.

Data collection: Knowledge of AKI was assessed through the use of validated closed-ended structured questionnaire that had 32 questions. This questionnaire was validated in a pilot study done in State Specialist Hospital Akure, Southwest Nigeria, using 20 respondents (nonnephrology doctors) who were not involved in the main study. The Cronbach's alpha internal consistency coefficient of the questionnaire was 0.72 .

The questionnaire had sections $\mathrm{A}$ and $\mathrm{B}$. Section A consists of questions on sociodemographic information, number of years of practice and department of the respondents. Section B consists of questions that assessed knowledge in areas of clinical features, types, and risk factors of AKI, potentially nephrotoxic medications, criteria for diagnosis and staging of AKI, newer biomarkers of AKI and indications for renal replacement therapy (RRT) in AKI.

Internal medicine, pediatrics, community medicine and family medicine were categorized as

DOI: http://dx.doi.org/10.4314/ejhs.v27i2.7 
medical specialty while general surgery, ear, nose and throat surgery, plastic surgery, orthopaedic surgery, ophthalmology, anesthesia/intensive care unit, obstetrics and gynaecology were categorized as surgical specialty.

A score of 1 point was given to each correctly answered question and the total score was calculated for each respondent. The maximum obtainable score was 32. A score of 24-32 points was considered as having good knowledge of AKI, 16-23 points as fair knowledge and <16 points as poor knowledge.

Ethical consideration: Ethical clearance was obtained from the Ondo state Ethical and Research Committee. Informed consent was obtained from each participant. All copies of the questionnaire were coded (without names), and confidentiality of responses was ensured throughout the study.

Data Analysis: Data were analyzed using the statistical package for social sciences (SPSS) version 17.0. Results were presented in tabular form. Univariate analysis was used in the description of characteristics of the study population. Discrete variables were presented as frequency and percentages. Chi-square test with trend was used to determine the significance of observed differences for ordinal categorical variables. $\mathrm{P}$ value $<0.05$ was considered significant.

\section{RESULTS}

Eighty-one respondents who were all nonnephrology doctors participated in the study consisting of $63(78 \%)$ males and $18(22 \%)$ females. The majority of the respondents were young and middle aged doctors; seventy-five $(94.9 \%)$ of them were between the ages 20 and 40 years. Forty $(49.4 \%)$ had $\leq 5$ years postgraduation experience. The median postgraduation experience of the respondents was 5.5(3) years. Sixty-one (78.2\%) worked in surgical specialty while the remaining worked in medical specialty (Table1).
Only $8(9.9 \%)$ had not received formal lectures on AKI in the past. Forty-nine (61.3\%) received AKI lecture during their undergraduate training, 4(5.0\%) during postgraduate training and $19(23.8 \%)$ during both undergraduate and postgraduate training. Sixty-six (82.5\%) had managed patients with AKI in the past while $70(87.5 \%)$ had referred patients with AKI to a nephrologist in the past (Table 1).

Table 1: Characteristics and Experiences of Study Population.

\begin{tabular}{|c|c|}
\hline Parameter & n $(\%)$ \\
\hline \multicolumn{2}{|l|}{ Age (years) } \\
\hline 20-30 & $35(44.3 \%)$ \\
\hline $31-40$ & $40(50.6 \%)$ \\
\hline 41-50 & $3(3.8 \%)$ \\
\hline $51-60$ & $1(1.3 \%)$ \\
\hline \multicolumn{2}{|l|}{ Gender } \\
\hline Male & $63(78 \%)$ \\
\hline Female & $18(23 \%)$ \\
\hline \multicolumn{2}{|l|}{ Years of Post-graduation experience } \\
\hline$\leq$ 5years & $40(49.4 \%)$ \\
\hline$>5$ years & $41(50.6 \%)$ \\
\hline \multicolumn{2}{|l|}{ Specialty } \\
\hline Medical & $17(21.8 \%)$ \\
\hline Surgical & $61(78.2 \%)$ \\
\hline \multicolumn{2}{|l|}{ Received Previous AKI lecture } \\
\hline Yes, during undergraduate training & $49(61.3 \%)$ \\
\hline Yes, during postgraduate training & $4(5.0 \%)$ \\
\hline $\begin{array}{l}\text { Yes, during both undergraduate and } \\
\text { postgraduate trainings }\end{array}$ & $19(23.8 \%)$ \\
\hline No & $8(9.9 \%)$ \\
\hline \multicolumn{2}{|l|}{ Managed AKI patient before } \\
\hline Yes & $66(82.5)$ \\
\hline No & $14(17.5 \%)$ \\
\hline \multicolumn{2}{|l|}{$\begin{array}{l}\text { Referred AKI patient to Nephrologist } \\
\text { before }\end{array}$} \\
\hline Yes & $70(87.5 \%)$ \\
\hline No & $10(12.5 \%)$ \\
\hline
\end{tabular}

Acute Kidney Injury (AKI)

Non-response excluded from each variable
Fifty-six (69.2\%) of the respondent had fair knowledge of AKI while knowledge was poor in

DOI: http://dx.doi.org/10.4314/ejhs.v27i2.7 
$24(29.6 \%)$. Only 1(1.2\%) of the respondents had good knowledge of AKI (Figure 1).

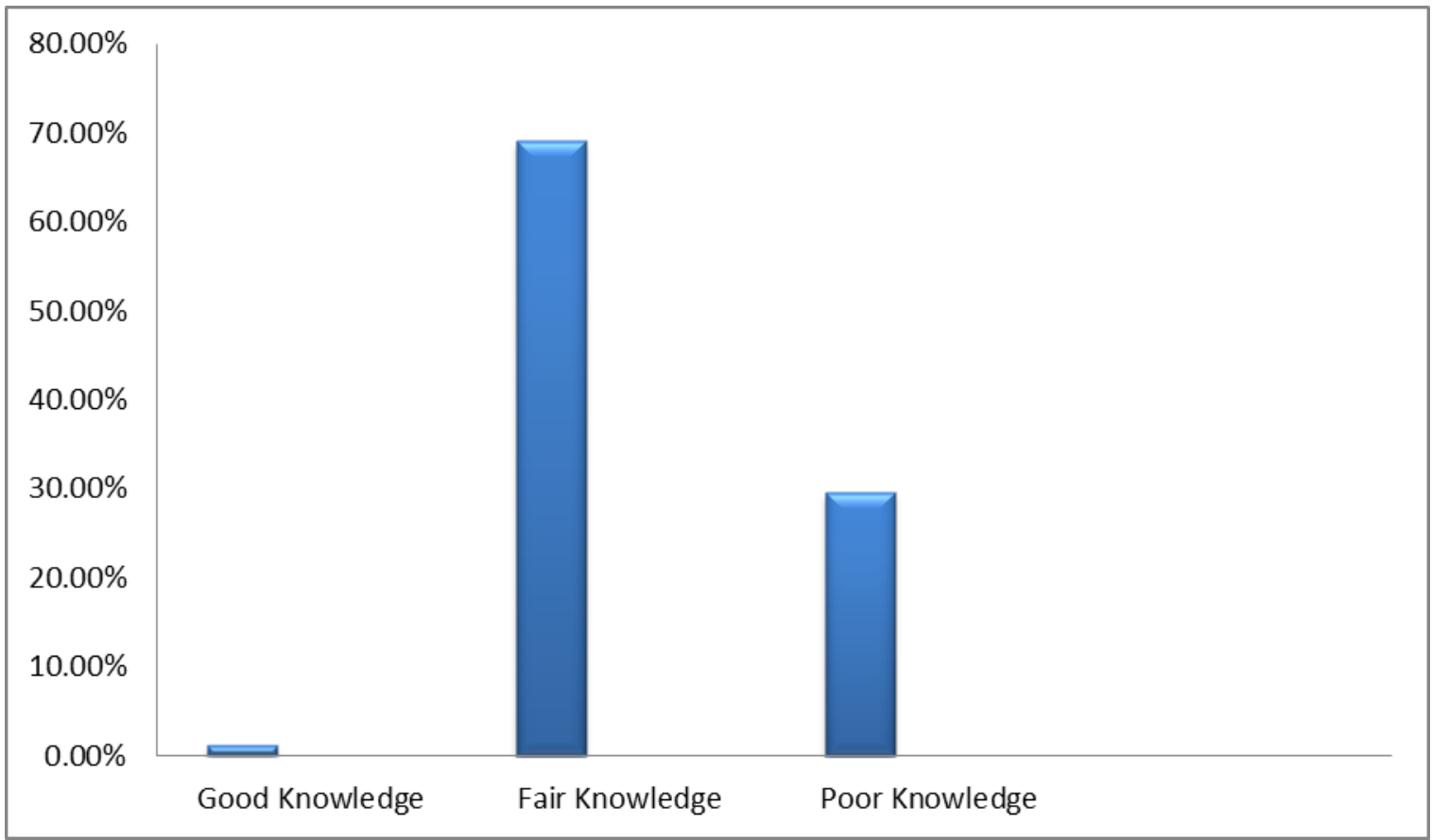

Figure 1: Knowledge of AKI among respondents

Only $33(40.7 \%)$ of the respondents knew that serum creatinine may be normal in patients with AKI while 42(51.9\%) knew that urine output may be adequate in AKI patients. About half of the respondents did not know that the elderly were at risk of developing AKI. Less than a third knew that furosemide, lisinopril and valsartan were potentially nephrotoxic while 67(82.7\%) knew that NSAIDs were nephrotoxic. The majority knew the types of AKI, although only 28(34.6\%) knew about the extension phase of acute tubular necrosis (Table 2)

Only twenty-four (29.6\%) and 19(23.5\%) of the respondents knew about Acute Kidney Injury Network (AKIN) and Kidney Disease Improving Global Outcome (KDIGO) criteria for AKI definition and staging. However, Risk, Injury,
Failure, Loss and End stage renal disease (RIFLE) criteria for AKI definition and criteria was known by $50(61.7 \%)$ of the respondents (Table 2 ).

Majority of the respondents did not know about newer AKI biomarkers. Thirteen (16\%) of the respondents knew that Neutrophil gelatinase associated lipocalin (NGAL) and Liver-fatty acid binding protein were newer AKI biomarkers while $22(27.2 \%)$ knew cystatin-C as newer AKI biomarker.

Only $7(8.6 \%)$ of the doctors knew the value of daily rise in serum creatinine or urea that will require dialysis in patients with AKI (Table 2).There was no significant association between knowledge of AKI and specialty $(\mathrm{p}=0.593)$ or years of practice $(\mathrm{p}=0.312)$ (Table 3$)$.

Table 2: Frequency of correct answers about AKI

DOI: http://dx.doi.org/10.4314/ejhs.v27i2.7 


\begin{tabular}{|c|c|c|}
\hline $\mathbf{S} / \mathbf{N}$ & QUESTIONS & $\begin{array}{l}\text { Frequency of correct answers } \\
\text { n(\%) }\end{array}$ \\
\hline 1 & The following may occur in AKI & \\
\hline 1.1 & Urine output may be reduced & $81(100 \%)$ \\
\hline 1.2 & Urine output may be normal & $42(51.9 \%)$ \\
\hline 1.3 & Serum creatinine may be normal & $33(40.7 \%)$ \\
\hline 2 & Risk factors for AKI include & \\
\hline 2.1 & Heart failure & $68(84 \%)$ \\
\hline 2.2 & Diabetes mellitus & $67(82.7 \%)$ \\
\hline 2.3 & Elderly & $41(50.6 \%)$ \\
\hline 2.4 & Liver disease & $57(70.4 \%)$ \\
\hline 2.5 & Chronic hypertension & $60(74.1 \%)$ \\
\hline 3 & Potentially Nephrotoxic medications include & \\
\hline 3.1 & Frusemide & $24(29.6 \%)$ \\
\hline 3.2 & NSAIDs & $67(82.7 \%)$ \\
\hline 3.3 & Co-trimoxazole & $41(50.6 \%)$ \\
\hline 3.4 & Lisinopril & $19(23.5 \%)$ \\
\hline 3.5 & Valsartan & $9(11.1 \%)$ \\
\hline 4 & Types of AKI include & \\
\hline 4.1 & Pre-renal AKI & $76(93.8 \%)$ \\
\hline 4.2 & Renal AKI & $77(95.1 \%)$ \\
\hline 4.3 & Post-renal AKI & $76(93.8 \%)$ \\
\hline 5 & Phases of Acute tubular Necrosis include & \\
\hline 5.1 & Initiation Phase & $65(80.2 \%)$ \\
\hline 5.2 & Extension Phase & $28(34.6 \%)$ \\
\hline 5.3 & Maintenance Phase & $52(64.2 \%)$ \\
\hline 5.4 & Recovery Phase & $67(82.7 \%)$ \\
\hline 6 & Criteria for AKI definition and staging include & \\
\hline 6.1 & RIFLE & $50(61.7 \%)$ \\
\hline 6.2 & APACHE & $10(12.3 \%)$ \\
\hline 6.3 & AKIN & $24(29.6 \%)$ \\
\hline 6.4 & KDIGO & $19(23.5 \%)$ \\
\hline 7 & Examples of new biomarkers of AKI include & \\
\hline 7.1 & NGAL & $13(16.0 \%)$ \\
\hline 7.2 & Liver-fatty acid binding protein & $13(16.0 \%)$ \\
\hline 7.3 & Hepatocyte growth factor & $9(11.1 \%)$ \\
\hline 7.4 & Cystatin-C & $22(27.2 \%)$ \\
\hline 8 & Indications for dialysis in AKI patients include & \\
\hline 8.1 & Anuria & $72(88.9 \%)$ \\
\hline 8.2 & Refractory pulmonary oedema & $68(84.0 \%)$ \\
\hline 8.3 & Daily rise in urea by $100 \mathrm{mg} / \mathrm{dl}$ & $7(8.6 \%)$ \\
\hline 8.4 & Daily rise in creatinine by $2 \mathrm{mg} / \mathrm{dl}$ & $7(8.6 \%)$ \\
\hline
\end{tabular}

DOI: http://dx.doi.org/10.4314/ejhs.v27i2.7 
Table 3: Association between knowledge of AKI, specialty and years of Practice

\begin{tabular}{lllll}
\hline & $\begin{array}{l}\text { Good } \\
\text { Knowledge }\end{array}$ & $\begin{array}{l}\text { Fair } \\
\text { Knowledge }\end{array}$ & $\begin{array}{l}\text { Poor } \\
\text { Knowledge }\end{array}$ & P-value \\
\hline $\begin{array}{l}\text { Specialty } \\
\text { Medical specialty }\end{array}$ & $0(0 \%)$ & $12(22.6 \%)$ & $5(20.8 \%)$ & 0.593 \\
$\begin{array}{l}\text { Surgical specialty } \\
\text { Years of Practice }\end{array}$ & $1(100 \%)$ & $41(77.4 \%)$ & $19(79.2 \%)$ & \\
$\begin{array}{l}\text { S 5years } \\
>5 \text { years }\end{array}$ & $0(0 \%)$ & $30(53.6 \%)$ & $10(41.7 \%)$ & 0.312 \\
\hline
\end{tabular}

Non-response excluded from each variable

\section{DISCUSSION}

There were significant deficiencies in the knowledge of AKI among the majority of the respondents in this study. Only $1(1.2 \%)$ of the respondents had good knowledge of AKI, $56(69.2 \%)$ had fair knowledge and the remaining $24(29.6 \%)$ had poor knowledge of AKI.

About $60 \%$ of the respondents did not know that serum creatinine may be normal in patients with AKI while only about $50 \%$ were aware of non-oliguric AKI. This shows that a significant proportion of the respondents may not be able to diagnose AKI in the early stages. This is similar to findings of Stevens et al who found that identification of key features of AKI was lacking among non-specialist doctors (13). Adequate knowledge of presentation of AKI is pivotal to making early diagnosis and improving outcomes. Half of the respondents in this study did not know that elderly persons were at increased risk of AKI. This is surprising because it is well established that the elderly have reduction in functional renal reserve, impaired renal autoregulation, defective fluid homeostasis and increased risk of drug nephrotoxicity, therefore making them highly susceptible to AKI (16). The finding of deficiency in risk assessment in this study was corroborated by reports of NCEPOD that found that risk assessment for AKI was poor among health workers (10). Muniraju et al also reported that only $37 \%$ of junior trainee doctors could identify two risk factors for AKI (17). Assessment of risk factors is key to prevention, early diagnosis and intervention in AKI.

Knowledge of potentially nephrotoxic drugs was poor among the respondents. Most of the respondents did not know that angiotensin converting enzyme inhibitors (ACEI), angiotensin receptor blocker (ARBs) and furosemide are potentially nephrotoxic. Some of these drugs are commonly used during in-patient care, including the peri-operative period $(18,19)$. This knowledge gap may prevent the doctors from reducing the doses or withdrawing these drugs in individuals at risk of AKI which is similar to report by Stewart et al (10). This may consequently worsen AKI or cause iatrogenic AKI which is the most common cause of iatrogenic renal disease with a case fatality of about $12 \%$ (16). Iatrogenic AKI is also associated with significantly high burden in terms of health cost, hospital stay, morbidity and mortality.

Knowledge of criteria for definition and staging AKI was also found to be poor in this study. Less than $30 \%$ of the respondents were aware of AKIN and KDIGO criteria. This knowledge gap may also prevent these doctors from diagnosing AKI promptly. In the same vein, majority of the doctors were not aware of newer AKI biomarkers. This therefore shows that the respondents were not abreast of recent information, developments and guidelines targeted at reducing the burden of AKI through prevention, early diagnosis and management.

Only $7(8.6 \%)$ of the respondents knew the values of daily rise in serum creatinine and urea that will require urgent renal replacement therapy (RRT) in patients with AKI. This is similar to findings amongst junior doctors in United Kingdom where $37 \%$ of them could not name a single indication for renal referral (10). Poor knowledge of indication for RRT may therefore delay referral to nephrologists.

The majority of the respondents who managed patients with AKI in the past had nephrologist's input. This is unlike a report by Khan et al which

DOI: http://dx.doi.org/10.4314/ejhs.v27i2.7 
showed that only $22 \%$ of acute renal failure patients were referred to nephrologists (15). However, nephrologists' input must be timely to have the desired effects on patient outcomes. Early nephrologists' referral of AKI patients has been shown to be associated with reduced risk of further deterioration in renal function, better utilization of hospital resources and better patients' outcomes (19-22).

There was no significant association between knowledge of AKI, specialty and years of practice among the respondents. This therefore implies that educational programs aimed towards improvement of AKI patients' care should be targeted at all doctors irrespective of their years of practice or specialty. Focused educational programs on improving knowledge and management of AKI have been reported to improve management of AKI and overall patients' outcomes (23-26).

The limitation of this study is the relatively small sample size, hence the findings cannot be generalized. However, this study is the first to assess knowledge of AKI among non-nephrology doctors in Southwest Nigeria. The study has also been able to identify the areas of significant knowledge gap in AKI which should be emphasized in organizing educational programs aimed at improving AKI care.

In conclusion, there were significant deficiencies in the knowledge of AKI among non-nephrology doctors in Ondo City, Southwest Nigeria. Identified areas of deficiencies were mode of presentation, risk factors, potentially nephrotoxic medications, criteria for AKI definition and staging, newer AKI biomarkers and indications for RRT. Educational programs such as lectures and seminars on AKI should be incorporated regularly into the continuing medical education for all cadres of doctors. This may improve their knowledge and capacity to prevent, diagnose and manage AKI patients satisfactorily.

\section{REFERENCES}

1. Li PK, Burdmann EA, Mehta RL. Acute kidney injury: global health alert. $J$ Nephropathology 2013;2(2):90-97.

2. Susatitaphong P, Cruz DN, Cerda J, Abulfaraj M, Alqahtani F, Koulouridis I et al. World incidence of AKI: a meta-analysis. Clin J Am Soc Nephrol 2013;8(9):1482-93

3. Koyner JL, Cerda J, Goldstein SL, Jaber BL, Liu KD, Shea JA. The daily burden of acute kidney injury: a survey of US nephrologists on world kidney day. Am J Kidney Dis 2014;64(3):394-401

4. Bamgboye EL, Mabayoje MO, Odutola TA, Mabadeje AF. Acute renal failure at Lagos University Teaching Hospital: a 10 year review. Ren Fail 1993;15(1):77-80.

5. Okunola OO, Ayodele EO, Adekanle AD. Acute kidney injury requiring haemodialysis in the tropics. Saudi J Kidney Dis Transpl 2012;23(6):1315-9.

6. Hobson C,Ozrazgat-Baslanti T, Kuxhausen A, Thottakkara P, Efron PA, Moore FA et al. Cost and mortality associated with postoperative acute kidney injury. Ann Thorac Surg 2014;97(1):111-117.

7. Schiffl H, Lang SM, Fischer R. Long term outcomes of survivor of intensive care unit acute kidney injury requiring renal replacement therapy: a 10 year prospective cohort study. Clin Kidney J 2012;5(4):297302.

8. Coca SG, Singanamala S, Parikh CR. Chronic kidney disease after acute kidney injury: a systematic review and metanalysis. Kidney Int 2012;81(5):442-448.

9. Praught ML,Shlipak MG. Are small changes in serum creatinine an important risk factor? Curr Opin Nephrol Hypertens 2005;14 (3):265-270.

10. Stewart J, Smith N, Kelly K, Mason M. Adding insult to injury: a review of the care of patients who died in hospital with a primary diagnosis of acute kidney injury (acute renal failure) A report by the National Confidential Enquiry into Patient Outcome and Death. 2009 available

http://wwwncepodorguk/2009akihtm2009 accessed on 05/06/16. 
11. Aitken E, Carruthers C, Gall L, Kerr L, Geddes C, Kingsmore D. Acute kidney injury: outcomes and quality of care. QJM 2013;106(4):323-332

12. Evans R, Rudd P,Hemmila U,Dobbie H, Dreyer G. Deficiencies in education and experience in the management of acute kidney injury among Malawian healthcare worker. Malawi Med J 2015;27(3):101-103

13. Stevens PE, Tamini NA, Al-Hasani MIC, Mikhail AI,Kearney E, Lapworth R. Nonspecialist management of acute renal failure. QJM 2001;94(10):533-400

14. Lewington AJP, Cerda J, Mehta RL. Raising awareness of acute kidney injury: A global perspective of a silent killer. Kid Int 2013;84(3):457-467

15. Khan IH, Catto GR, Edward N, Macleod AM. Acute renal failure: factors influencing nephrology referral and outcome. QJM 1997;90(12):781-785

16. Davidman M, Olson P, Kohen J, Leither T, Kiellstrand C. Iatrogenic renal disease. Arch Intern Med 1991;151(9):1809-1812

17. Muniraju TM, Lillicrap MH, Horrocks JL, Fsher JM, Clark RM, Kanagasundaram NS. Diagnosis and management of AKI: deficiencies in knowledge base of nonspecialist, trainee medical staff. Clinical Medicine 2012;12(3):216-221

18. Borthwick E, Ferguson A. Peri-operative acute kidney injury: risk factors, recognition, management and outcomes. BMJ 2010;341:3365.doi10.1136/bmj.c3365

19. Mehta RL, Pascual MT, Soroko S, Chertow GM, Group PS. Diuretics, mortality and nonrecovery of renal function in acute renal failure. JAMA 2002;28(20):2547-2553
20. Hegarty J, Miiddleton RJ, Krebs M, Hussain H, Cheung C, Ledson T. Severe acute renal failure in adults: place of care, incidence and outcomes. QJM 2005,98(9):661-666

21. Perez-Valdivieso JR, Bes-Rastrollo $M$, Monedero P, de Irala J, Lavilla FJ. Prognosis and serum creatinine levels in acute renal failure at the time of nephrology consultation: an observational cohort study. BMC Nephrol 2007;8(14) doi:10.1186/1471-2369-8-14

22. Balasubramanian G, Al-ly Z. Moiz A, Rauchman M, Zhang Z, Gopalakrishman R. Early nephrologist involvement in hospitalacquired acute kidney injury; a pilot study. Am J Kidney Dis 2011;57(2):228-234

23. Forde C, Mc Caughan J, Leonard N. Acute kidney injury: It's as easy as ABCDE. $B M J$ Quality Improvement Reports 2013;2(1)u200370.w326.doi:10.1136/bmj quality

24. Bhagwanani A, Carpenter R, Yusuf A. Improving the management of AKI in a district general hospital. Introduction to the DONUT bundle. BMJ Quality Improv Report. 2014;u202650.w1235doi:10.1136/bmjquality. u202650.w1235

25. Trotter N, Doherty C, Tully V, Davey P, Samira B. Improving recognition of postoperative AKI. BMJ Quality Improvement. BMJ Qual Improv Report 2014;3: doi:10.1136/ bmjquality.u205219. w2164.

26. Brady P, Gorham J, Kosti A, Segliman W, Courtney A, Mazan K et al. "SHOUT" to improve quality of care delivered to patients with acute kidney injury at Great Hospital. BMJ Qual Improv Report 2015;4: doi:10.1136/ bmjquality.u207938.w3198 